\title{
Estudos de recepção na América Latina: contribuição para atualizar o panorama ${ }^{1}$
}

\author{
Nilda Jacks ${ }^{1}$ e Daiane B. Menezes ${ }^{2}$
}

\begin{abstract}
Resumo: Este artigo faz um panorama da pesquisa latino-americana a partir de um exame realizado por vários pesquisadores sobre os estudos de recepção em seus países, publicado em uma edição especial da Revista Diálogos de la Comunicación (n.73/2006). Apesar de eixos comuns trazidos pela dependência inicial da pesquisa norte-americana e européia e sob a influência posterior gerada nos principais países da região, há certas características nacionais que diferenciam alguns países, as quais serão exploradas aqui, como a institucionalização dos estudos, que variou de acordo com situação política e o cenário midiático, a tradição do campo em cada país e suas influências externas, as temáticas exploradas e as características específicas da produção científica em comunicação desses países.
\end{abstract}

Palavras-chave: Estudos de Recepção; América Latina; Pesquisa.

\begin{abstract}
This article is an overview of Latin American research from an examination conducted by several researchers on the reception studies developed in their countries, which is published in a special edition of the Journal Diálogos de la Comunicación (n.73 / 2006). Despite common axes brought by the initial dependence of the North American and European search and under the later influence generated in the main countries of the region, there are certain national characteristics that differentiate certain countries, which will be explored here, as the institutionalization of the studies, which varied in accordance with the political situation and media scenario, the tradition of the area in each country and their external influences, the themes explored and specific characteristics of the communication scientific production in these countries.
\end{abstract}

Keywords: Reception Studies; Latin America; Research.

${ }^{1}$ Doutora em Ciências da Comunicação/ ECA-USP. Professora da UFRGS. Endereço eletrônico: njacks@ufrgs.br.

2 Mestranda em Ciências Sociais/PUCRS. Graduação em Comunicação Social Jornalismo/UFRGS. Endereço eletrônico: daianebm@hotmail.com. 
Resumen: Este artículo traza un panorama de la investigación latinoamericana desde un análisis hecho por investigadores al respecto de los estudios en recepción desarrollados en sus respectivos países y que fuera publicado en una edición especial de la revista Diálogos la Comunicación (No. 73/2006). A pesar de compartir ejes comunes establecidos por la dependencia inicial con la investigación norteamericana y europea, además de la influencia posterior de los estudios generados en los principales países de la región, se destacan ciertas características nacionales que diferencian a algunos de ellos, como por ejemplo, la institucionalización de los estudios los cuales varían de acuerdo con la situación política y el escenario mediático, la tradición de la investigación en el área en cada país y las influencias externas que ellos han recibido, los temas explorados y las características específicas de la producción en comunicación en cada uno de ellos.

Palabras-claves: Estudios de Recepción ; América Latina; Investigación.

Resumé: Cet article est un panorama de la recherche des pays d'Amérique Latine en partant d'un examen des recherches réalisées par plusieurs chercheurs sur les études de réception dans leur pays, qui est publiée dans une édition spéciale du maganize Diálogos de la Comunicación (n.73 / 2006). Malgré des essieux communs apportés par la dépendance initiale de la recherche de l'Amérique du Nord et d'Europe et sous l'influence généré plus tard dans les principaux pays de la région, il ya certaines caractéristiques nationales qui différencient certain pays, qui seront étudiées ici: l'institutionnalisation des études, qui varie selon la situation politique et des médias scénario, la tradition du champ dans chaque pays et leurs influences externes, les thèmes traités et les caractéristiques spécifiques de la production scientifique dans communication de ces pays.

Mots-clés: Études de Réception, Amérique Latine; Recherche.

\section{Introdução}

Este texto examina de forma transversal a análise realizada por vários pesquisadores latino-americanos sobre os estudos de recepção produzidos em seus países, a qual está publicada na Revista Diálogos de la Comunicación (n.73), coordenada por Valerio Fuenzalida e Nilda Jacks (2006) ${ }^{2}$.

A partir destas considerações, o que faremos aqui é traçar um panorama que aponte as diferenças e semelhanças entre as pesquisas realizadas na parte latina do continente ${ }^{3}$, indicando os contextos que deram estes contornos. 


\section{Institucionalização dos estudos: situação política e cenário midiático}

Na maior parte dos países os estudos de recepção tiveram seu momento de emergência durante os anos 80, localizando-se mais para o início ou mais para o fim da década segundo as condições institucionais do campo e/ ou da situação política vigente.

Na Argentina, Chile e Brasil coincide com o fim das ditaduras, sendo que no Chile o desenvolvimento inicial aconteceu fora das universidades ${ }^{4}$, assim como no Peru e na Colômbia onde também foram realizadas nas ONGs, embora em contextos políticos diferentes.

Em alguns países as ditaduras esvaziaram o debate por pressão do regime ou por fuga de pesquisadores, sendo o México o país que acolheu boa parte dos teóricos exilados, como os argentinos. Segundo Jorge González (1998) esse fato fez toda a diferença, pois

no fueron los intercambios científicos, es decir la propia dinámica del campo, sino una perturbación externa, - -la represión militar en América del Sur- que mediante redes de amigos y conocidos, nos puso en contacto directo con colegas de sólida formación que vinieron a refrescar el ya de por si viciado ambiente del campo científico mexicano de mediados de los setentas, pleno de certezas de corte positivista o bien de corte que se llamaba "crítico". Con ellos llegaron a México otras bibliografías, autores, perspectivas y problemáticas que influyeron definitivamente en la reorientación de los temas de investigación y, a su vez, fueron influidos por las diversas tradiciones y corrientes que se desarrollaban en México.

Em quase todos os casos, a presença da ditadura resultou na definição de certas temáticas e problemáticas de pesquisa, o que excluiu o tratamento da recepção, ocupados que estavam os pesquisadores no destrinchamentos ideológicos das mensagens e meios, uma vez que estes estavam em aliança com os governos autoritários, retardando o estabelecimento do debate sobre a relação entre meios e audiência.

No Chile e no Brasil, particularmente, o processo de resistência impulsionou a perspectiva da leitura crítica dos meios, em ambos os casos sob a concepção pedagógica proposta por Paulo Freire em a Pedagogia do Oprimido. Na Colômbia e Peru foram as fragilidades democráticas e os processos revolucionários os que deram relevo aos assuntos como violência, política e cidadania como base para pensar a comunicação, e mais tarde para os processos de recepção. O caso mais extremo foi o de El Salvador que devido à guerra civil retardou a implantação da pesquisa até recentemente.

As ditaduras tiveram, no entanto, influências diversas na configuração das indústrias culturais, um dos fatores que repercute no campo da pesquisa em comunicação, 
pois a relação entre política e mercado se faz sentir tanto na afirmação da pesquisa para o mercado ${ }^{5}$ quanto para a acadêmica preocupada com ele. Enquanto em alguns países apenas TVs estatais funcionavam durante a ditadura, em outros, as TVs comerciais surgiram durante o próprio período de exceção. No Chile, "el riguroso control militar de todo el sistema televisivo postergó la introducción de cualquier forma de TV comercial privada. Solamente a fines de la dictadura [aparecen os] canales privados” (FUENZALIDA, 2006, p.48). Na Venezuela, ao contrário, foi durante o período ditatorial que surgiram as TVs comerciais: “entre ese 1952 y 1958 tendremos ya un parque de seis estaciones de televisión, de las cuales cinco serán de carácter comercial/privado”, afirma Marcelino Bisbal (2006, p.108). Algo muito semelhante ocorreu com o Brasil, em que um ano após a ditadura foi criada a Rede Globo, maior rede de televisão brasileira, no lugar da Rede Tupi, que entrou em um processo de falência no final dos anos 70. Surgiram também outras três redes nacionais: a Bandeirantes, o SBT e a Educativa, e, com cobertura parcialmente nacional, a Rede Manchete (CAPPARELLI, 1982). Obviamente só isto não explica o desenvolvimento do campo e a definição de objetos de estudo, uma vez que tanto a pesquisa brasileira quanto a venezuelana, por exemplo, emergem no mesmo momento, tendo sofrido ditaduras em épocas diferentes, assim como o caso do México que não sofreu ditadura neste período e acompanhou aqueles países na afirmação dos estudos de recepção.

Nos casos do Peru e da Colômbia, por exemplo, a fragilidade democrática levou a pesquisa a problematizar a violência e a cultura política respectivamente, indicando a pertinência de considerar o cenário político para entender as condições de produção científica, conjugadas com os aspectos internos ao campo e a estrutura midiática. Esta foi a situação da maioria dos países durante a década de 80, com exceção do Paraguai, que ainda não construiu o cenário para o aparecimento dos estudos de recepção, conseqüência de fatores internos e externos ao campo científico. Os demais países começam suas pesquisas na década de 90, já sob o forte influxo do trabalho realizado nos países pioneiros.

\section{Tradição do campo e influências externas}

Em quase todos os países as pesquisas de recepção tiveram como cenário original os estudos dos efeitos, tributários da tradição funcionalista norte-americana, quase sempre paradoxalmente em consonância com a teoria frankfurtiana, outra tradição vigente nos anos 60 e 70 que marcou o desenvolvimento dos estudos de comunicação latino- 
americanos. Pode-se indicar como exceção o caso da Argentina que muito cedo incorporou a contribuição de Gramsci sobre as culturas populares abrindo um debate mais próximo aos estudos culturais, fato que aconteceu no Brasil pelo menos uma década depois, momento que aquele autor é introduzido no debate das ciências sociais (COUTINHO, 1988). Estamos sempre falando, é claro, dos estudos de recepção desenvolvidos no âmbito da pesquisa em comunicação, que teve influência definitiva, em quase todos os países, das teorias propostas por Martin-Barbero, García Canclini e Guillermo Orozco, entre os mais destacados.

É através de Martin-Barbero que a Colômbia projeta-se como país irradiador do debate sobre recepção e uso dos meios, entretanto, também sofre influência da produção brasileira, chilena e mexicana (MARTIN-BARBERO, 2006). Esta última também é responsável por inseminar vários aspectos da produção de muitos países, uma vez que conta com muitos pesquisadores dedicados à questão e um campo acadêmico bem estruturado, como também é o caso do Brasil, o que possibilita a produção e circulação da pesquisa. Em se tratando da relação entre comunicação e educação pode-se afirmar que o Chile também é um pólo irradiador, tendo-se em conta a contribuição do chileno Valério Fuenzalida e sua equipe.

Houve, entretanto, países que angularam estas influências com a produção local, tanto da área da comunicação como das ciências sociais de modo geral. São os casos, por exemplo, do Brasil que desenvolveu uma perspectiva devedora dos trabalhos de Paulo Freire e da Argentina com relação a Eliseo Verón e o caso de ambos com o pensamento nacional. Além do Brasil, Paulo Freire também inspirou a pesquisa chilena, como já foi dito, uma vez que o trabalho desenvolvido lá estava muito vinculado à educação para os meios. De qualquer maneira, o que vincula a experiência realizada na maioria dos países que tiveram uma produção na área foram, mais cedo ou mais tarde, os estudos culturais, quer tenha sido mediado pela discussão estabelecida no continente, quer pela discussão européia trazida por teóricos nacionais. Foi a configuração do campo da pesquisa que ordenou esta relação, ou seja, especula-se que quanto menos institucionalizado mais dependente do debate externo, no caso a produção dos países vizinhos, como aconteceu com El Salvador e em certa medida o Uruguai. Na situação oposta encontram-se a Venezuela e o Chile que articularam sua pesquisa a teóricos não latino-americanos como 
Jauss, Morley, Jensen e Lull, entre outros, como assinalam os analistas dos respectivos países (BISBAL; FUENZALIDA, 2006).

\section{Temáticas exploradas}

Superados os anos mais difíceis, as temáticas emergentes a partir do final dos anos 80 e durante os 90 foram os estudos de recepção de telenovela, na Argentina, Uruguai, Brasil, Colômbia, Peru, México e Chile, alguns na esteira da cultura popular outros no entendimento do gênero ficcional e das práticas cotidianas. Na relação entre comunicação e educação, os estudos de recepção ganharam mais evidência na Argentina, Bolívia, Chile, Venezuela, México, El Salvador e Peru. Neste último muito perpassado pelas questões da cultura política, da cidadania e também da recepção crítica, presentes ainda na produção do Chile, México e Venezuela, embora neste último aparentemente com menos vigor, como parece também ser o caso da Bolívia.

No caso brasileiro houve o desenvolvimento de um projeto de longo prazo liderado pela União Católica Brasileira de Comunicação Social (UCBC) em conjunto com a Igreja Católica. O projeto iniciou em 1979 e entre suas estratégias principais estavam o desenvolvimento de cursos de educação para os meios e a publicação da coleção Para uma Leitura Crítica, preparada por teóricos da área e composta de manuais para leitura de televisão, jornal, história em quadrinhos, publicidade etc.

Preocupadas com o consumo cultural, outra chave para pensar os processos de recepção, estão a pesquisa argentina, chilena, colombiana, equatoriana, venezuelana, portoriquenha e a do México, de onde irradiou diferentes experiências no trato deste fenômeno. Na Argentina e México o consumo cultural é mais pensado na vinculação com a temática das identidades culturais, na Colômbia é em relação com a cultura juvenil assim como no Equador. Em Porto Rico é na relação com o consumo midiático, muito semelhante ao caso do México, que também investiga nesta área. No Peru a questão das identidades aparece articulada com as do gênero feminino. Temáticas muito particulares são tratadas na Bolívia, Peru, Uruguai, El Salvador, México e Porto Rico. No caso da Bolívia está a preocupação com a relação entre comunicação e desenvolvimento, no Peru com a comunicação alternativa e novas tecnologias, no Uruguai e México com os talk shows, sendo que no primeiro ainda há interesse em entender o processo de comunicação publicitária na relação com os consumidores. A pesquisa em El Salvador tem um perfil 
conseqüente com a experiência de guerra e de intensa emigração, revelada pelas temáticas da política, liberdade de expressão, audiência rural e transnacional, esta também explorada pela pesquisa mexicana. Com uma situação política menos dramática, em Porto Rico as questões tratam de processos culturais, consumo, religião, imprensa sensacionalista, identidade cultural caribenha.

No Brasil a questão das identidades, em geral, é tratada do ponto de vista daquelas que não são hegemônicas, ou seja, as que estão fora do eixo Rio-São Paulo, direcionando os estudos para as culturas regionais frente aos processos de recepção de meios com cobertura nacional.

\section{Características específicas}

Apesar de eixos comuns trazidos pela dependência inicial da pesquisa norteamericana e européia e depois da gerada nos principais países da região, que ainda não alcançou devidamente o Equador ${ }^{6}$ e o Paraguai, há certas características nacionais que diferenciam a produção de alguns países. Porto Rico, em especial, parece localizar-se em uma encruzilhada, pois vive a ambigüidade de ser ao mesmo tempo latino e norteamericano, o que se reflete visivelmente na pesquisa no que se refere aos objetos e temas de estudo, além das abordagens teórico-metodológicas. A Argentina sobressai-se pela reflexão teórica e a crítica aos estudos de recepção, uma vez que a pesquisa empírica é realizada em menor grau, tanto como repercussão da tradição acadêmica ${ }^{7}$, quanto pela falta de recursos para o trabalho empírico. Ao contrário, o grande desenvolvimento de pesquisa empírica é a característica da pesquisa realizada no Brasil e no México, talvez os dois lugares com maior produção, tendo como resultado uma forte contribuição metodológica e de conhecimento da realidade empírica sobre processos de recepção de diversos meios em contextos sócio-culturais variados. Isto não alivia, entretanto, a crítica que o próprio campo realiza sobre a produção existente. No primeiro caso, os problemas maiores são estudos despolitizados, uma vez que audiência é tomada em si mesma e o receptor como um sujeito coerente; no segundo seria a dualidade entre estudos midiáticos e culturalistas (OROZCO GÓMEZ; TORRE, 2006), embora, por outro lado, os pesquisadores mexicanos tenham forte tradição de estudos multidisciplinares que apontam para a conjugação destas duas tendências. Como no caso brasileiro, a pesquisa boliviana também é tida como despolitizada, além de apresentar uma tendência constatacionista, que abandona o 
estrutural, tornando os estudos pouco críticos, pois "se comenzó a sugerir que el poder estaría concentrado en el lado del receptor, olvidando que entre emisor y receptor hay una relación dialéctica que tensiona los intereses y poderes de ambos” (CRESPO, 2006, p.31).

Na busca da superação de problemas metodológicos como este se destacam Peru e México, sendo que este tem contribuído com proposição de modelos teóricos e metodológicos. No extremo de tudo isso se encontra o Paraguai, onde inexiste a reflexão sobre a recepção.

O divórcio entre a pesquisa de mercado e a acadêmica é apontado pelo Chile e pelo Brasil, embora deva ser um problema generalizado, assim como a falta de sistemas de informação sobre a produção nacional e regional e de apoio financeiro para o trabalho empírico. Em El Salvador, por exemplo, "las publicaciones académicas sobre comunicación son reducidas e incipientes y la cultura de la discusión interinstitucional inició hace algunos años pero todavía no ha adquirido el calor de un intercambio continuo” (Parducci, 2006, p.117). Além disso, “el problema de la difusión de los resultados se complejiza al no tener publicaciones periódicas, como revistas, y al tener unas políticas muy malas de distribución de libros” (Parducci, 2006, p.122). O mesmo acontece em Porto Rico, onde "los trabajos que se han realizado y/o publicado hasta el momento están dispersos y poco se conoce de los esfuerzos de uno y otro programa de comunicación o de los investigadores” (RENGIFO, 2006, p.126).

No caso equatoriano, o problema também é a "seria dificultad para acceder a la información pertinente, especialmente en lo atinente a tesis de pregrado y posgrado” (MONTÚFAR, 2006, p.72). Ou seja,

no hay una conciencia sobre la importancia de la información y, por tanto, no hay una “cultura de la información” (registros, sistematizaciones, difusión y diseminación, accesibilidad, etc.) más grave aún pues los sistemas de información son un insumo básico de la investigación. Muchas instituciones no tienen página web o si la tienen suele ser muy elemental y desactualizada, son escasísimas las que tienen un servicio eficiente y completo. Hay un celo profundo para entregar información (Ibidem) ${ }^{8}$.

Afora os problemas de divulgação da produção científica, que implica no acesso à informação, comuns em muitos países, há o desinteresse pela pesquisa acadêmica em si, portanto, não há investimento nem para formação de pesquisadores, nem para dar suporte à produção científica. 


\section{As contribuições para o campo: à guisa de conclusão}

Decorrentes dos elementos estruturais e conjunturais que conformaram cada experiência nacional, podemos destacar as contribuições de alguns países para a constituição de uma produção de caráter e conteúdo latino-americano sobre processos de recepção. Assim, da Argentina pode-se indicar que a reflexão aportou saberes sobre a vinculação dos processos de recepção com o poder e com a constituição da subjetividade a partir de teorias da comunicação, segundo afirmam as pesquisadoras Florencia Saintout e Natalia Ferrante (2006). É de domínio geral, também, que as abordagens de Eliseo Verón sobre as condições de reconhecimento contribuíram sobremaneira para entender a relação entre produção e recepção.

Identificado de maneira semelhante é o caso da Leitura Crítica da Comunicação (LCC), contribuição original brasileira para a educação para os meios, produzida no início dos anos 80, embora alvo de críticas por seu caráter eminentemente pedagógico e intervencionista. De outro lado, há uma produção posterior caracterizada por uma diversidade de enfoques que dão uma riqueza à experiência brasileira, possibilitando muitas explorações teóricas e metodológicas a partir das propostas latino-americanas articuladas com as tendências internacionais e locais.

Com relação ao Chile, podemos pontuar a original exploração da relação afetiva e lúdica dos receptores com os meios e as mensagens massivas. Em termos da exploração metodológica, a etnografia da audiência é utilizada para revelar o contraste entre a fala captada por técnicas de entrevista com a conduta e as práticas dos receptores nas pesquisas realizadas tanto dentro como fora da universidade. Em outras palavras, a investigação etnográfica, justamente "busca integrar la observación de las conductas cotidianas de consumo medial en el hogar con las verbalizaciones de significación. Tal comprensión del consumo televisivo en situación de recepción da mejor cuenta de la tradicional contradicción entre las opiniones verbalizadas por la audiencia y las conductas manifestadas” (FUENZALIDA, 2006, p.50). Quase desnecessário destacar ainda a experiência do CENECA sobre a educação para os meios, como aconteceu no Brasil, Peru e no México, sob outras perspectivas.

A Colômbia, mesmo com diferentes contribuições, é reconhecida através da figura de Jesus Martin-Barbero como o país de onde irradiou a teoria das mediações, grande contribuição para a fermentação dos estudos de recepção em todo o continente e fora dele. 
Experiência importante e uma grande contribuição para ser aproveitada pelo restante dos países, vem do Peru. Trata-se da implantação observatórios da audiência com foco nas práticas dos receptores, cujo objetivo é observar o fenômeno da cidadania midiática, chamando a atenção para a necessidade de "ingresar valientemente al campo de la interpretación, identificar fenómenos explícitos e implícitos... Salir de la pregunta e ir a los imaginarios y supuestos posibles de cada respuesta como de la trama desde la cual se dijeron las respuestas o tendencias, actitud indispensable para poder luego regresar a la estadística o a lo dicho” (MORENO, 2006, p.94).

O Uruguai apesar de retardatário e com pouca circulação de sua produção, tem contribuído através de um grupo de pesquisadores com um programa de pesquisa que se dedica a recuperar a memória da recepção dos meios, isto sem deixar de atender à emergência das novas tecnologias midiáticas com explorações metodológicas sobre a relação do usuário com a internet.

Tanto quanto a Colômbia, mas de forma mais diversificada, o México é um país de onde irradiaram várias propostas teórico-metodológicas para entender a relação da audiência e receptores com os meios de comunicação. De lá vem a contribuição de Garcia Canclini para estudar o consumo cultural, a teoria das multi-mediações proposta por Guillermo Orozco para analisar especificamente a relação com a televisão, embora passível de entender outros meios, e a experiência do Programa Cultura fundado e coordenado por muito tempo por Jorge Gonzalez e Galindo Cáceres, os quais se dedicaram a estudar a telenovela no rastro das articulações entre cultura popular e de massa.

Salvo algum lapso, estas são as contribuições mais destacadas pelos pesquisadores que produziram este retrato da pesquisa latino-americana nestes meados da década em curso, cujo porvir foi pensado pelos analistas mexicanos ao indicar que "los estudios de caso deben leerse desde lo macro, comparando su información con las condiciones que desde la producción mediatica conforman a los públicos, incorporando la dimensión histórica y triangulando información de naturaleza cuantitativa”. Além disso, dizem que são necessárias “mejores condiciones para el trabajo en equipo y en colaboración, la puesta en común de resultados mediante canales de divulgación entre investigadores y hacia otras áreas de estudio para nutrirlas con sus aportes” (OROZCO GÓMEZ; TORRE, 2006, p.141). 


\section{Referências}

BISBAL, Marcelino. Recepción y televisión en Venezuela: itinerario de una línea investigativa. Dia-logos de la Comunicación, n.73, 2006.

CAPPARELLI, Sérgio. Televisão e capitalismo no Brasil. Porto Alegre, Editora LPM.

COUTINHO, Carlos Nelson; NOGUEIRA, Marco Aurélio. Gramsci e a América Latina. Rio de Janeiro. Paz e Terra, 1982, 1988.

CRESPO, Marcelo Guardia. Irrupción y proyecciones de los estudios de recepción en Bolivia. Dialogos de la Comunicación, n.73, 2006.

FUENZALIDA, Valerio. Estudios de audiencia e recepción en Chile. Dia-logos de la Comunicación, n.73, 2006.

GONZALEZ, Jorge (1998) La Voluntad de Tejer: Análisis Cultural, Frentes Culturales y Redes de Futuro. In: Razón y Palabra. Número 10, Año 3, Abril-Junio. Disponível em: $<$ http://www.cem.itesm.mx/dacs/publicaciones/logos/anteriores/n10/gonzalez2.htm> Acesso em: 22/06/2007.

GOMES, Itania Maria Mota. Efeito e Recepção: a interpretação do processo receptivo em duas tradições de investigação sobre os media. Rio de Janeiro: E-Papers Seviços Editoriais, 2004.

OROZCO GÓMEZ, Guillermo; TORRE, María Rebeca Padilla de la. Los estudios de recepción en México. Un itinerario. Dia-logos de la Comunicación, n.73, 2006.

Jacks, Nilda; Escosteguy, Carolina. Comunicação e Recepção. São Paulo: Hacker, 2005.

MARTIN-BARBERO, Jesús; TÉLLES, Marla Patricia. Los estudios de recepción y consumo en Colombia. Dia-logos de la Comunicación, n.73, 2006.

MONTÚFAR, Fernando Checa. Los estudios de recepción en Ecuador: paradojas, vacíos y desafíos. Dia-logos de la Comunicación, n.73, 2006.

MORENO, Rosa María. Declives en la investigación en favor de la vigilancia ciudadana: estudios de recepción mediática en Perú. Dia-logos de la Comunicación, n.73, 2006.

PARDUCCI, Amparo Marroquín. El Salvador: (Re)dibujando audiencias. Dia-logos de la Comunicación, n.73, 2006.

RENGIFO, Guadalupe Escalante. Tramas de la investigación en comunicación en Puerto Rico: una aproximación a los estudios de recepción. Dia-logos de la Comunicación, n.73, 2006.

SAINTOUT, Florencia; FERRANTE, Natalia. Los estudios de recepción en Argentina hoy: rupturas, continuidades y nuevos objetos. Dia-logos de la Comunicación, n.73, 2006.

SERATINI, Diana. Estudios de recepción desde la universidad en Paraguay. Las memorias de licenciatura de la carrera de ciencias de las comunicación de la U.C. Dia-logos de la Comunicación, n.73, 2006. 
VILELA, Rosario Sánches. Enfoques de la recepción en el Uruguay. Dia-logos de la Comunicación, n.73, 2006.

${ }^{1}$ Texto apresentado no painel "Estudios de recepción en América Latina”, que fazia parte do eixo temático "Comunicación, Cultura y Política". Congreso Latinoamericano y Caribeño de Ciencias Sociales. FLACSO. Quito, Nov. 2007.

${ }^{2} \mathrm{O}$ referido dossiê faz parte de um primeiro movimento para conhecer o cenário latino-americano hoje, o qual dá suporte para uma pesquisa que está em andamento, que se propõe a conhecer de perto a produção de teses e dissertações produzidas em cada país da região.

${ }^{3}$ Não participaram da publicação pesquisadores das Guianas e dos países da América Central, com exceção de El Salvador e Porto Rico.

${ }^{4}$ Em organizações como CENECA (Centro de Indagación y Expresión Cultural y Artística) e ILET (Instituto Latinoamericano de Estudios Transnacionales), segundo Fuenzalida (2006).

${ }^{5}$ Nem todos os pesquisadores contextualizaram o papel da pesquisa realizada no mercado como decorrência do desenvolvimento da indústria cultural em cada país, a qual também redefiniu o campo profissional e do ensino da comunicação. Estão bem explícitos os casos do Brasil e do Chile, cuja estrutura dos meios implantou-se fortemente durante a década de 70 e 80 trazendo repercussões para a pesquisa desenvolvida nas universidades.

${ }^{6}$ Apesar de o país ter "las matrices de ocho organizaciones internacionales de comunicación: CIESPAL, OCIC-AL, UNDA-AL, UCLAP, AMARC, ALER, PROA y el Proyecto Latinoamericano para Medios de Comunicación de la Friedrich Ebert Stiftung” isto teve efeitos pequenos no campo da comunicação e da pesquisa (MONTÚFAR, 2006, p.72).

${ }^{7}$ Tanto a Argentina quanto o Uruguai tem raízes nos estudos literários e na estética da recepção. A primeira especialmente com Eliseo Verón e o segundo com Wolfang Iser e Umberto Eco.

${ }^{8}$ El caso de las empresas encuestadoras es patético, no sólo que creen haber inventado el agua tibia, sino que quieren patentarla. Se negaron a entregar información aduciendo confidencialidad, desconfianza profesional, temor de que les “copien” metodologías y les "pirateen” resultados, pese a la insistencia de que sólo queríamos datos generales sobre el tipo de investigaciones que realizan, temas y frecuencias (MONTÚFAR, p.72). 